\title{
Novel Voltage Stability Index for Electric Power System Monitoring
}

Original Scientific Paper

\author{
Oukennou Aziz \\ ENSEM, Hassan II University \\ Advanced Control of Electrical Systems Team - LESE \\ Casablanca, Morocco \\ a.oukennou@uca.ma \\ Sandali Abdelhalim \\ ENSEM, Hassan II University \\ Advanced Control of Electrical Systems Team - LESE \\ Casablanca, Morocco \\ abdelhalim.sandali@uqtr.ca
}

\begin{abstract}
This paper aims to develop a novel voltage stability index (NVSI) to evaluate and detect the voltage collapse proximity in the power system. This NVSI is based on the combination of two indices and the approximation made on the difference in angle between the sending bus and the receiving one in the power system. Compared to indices developed in the literature, the advantage of the new voltage stability index (NVSI) is that it can be computed very quickly and easily from power flow results, such as voltages, magnitudes and angles. The static and dynamic studies have been carried out on the IEEE 14-bus test system using PSAT Software. The proposed index has shown more sensitivity and simplicity, and that it can be used as a monitoring tool.
\end{abstract}

Keywords - dynamic analysis, load variation, static analysis, voltage collapse, voltage stability index

\section{INTRODUCTION}

Nowadays, power grid failure has become one of the problems that operators and electric managers mostly face as it has enormous economic costs and social impacts [1]. Indeed, despite considerable efforts and equipment installed to control the power system, several blackouts have been recorded in the world [2-3], which claim that the tools used by operators are still less efficient and the fragile area in the power system is still not well located and therefore unreinforced. Voltage instability, which has attracted the attention of several researchers in power systems, has presented the major causes of grid failure and subsequently blackouts in recent decades [4-5]. The analysis of this phenomenon was then mandatory in order to provide solutions. It was conducted by using a static approach, where voltage stability is evaluated after contingencies without studying the transients during the change from an operating state to another, or a dynamic analysis, where power system behavior is evaluated and the transient analysis is taken into account. In so doing, several methods have been proposed, such as the traditional P-V and Q-V curves, the principle of which is based on load variation at one bus of the power system at time [6], which requires more time to be performed. Modal analysis was studied by Gao B et al. [7] to estimate the voltage collapse proximity. This method comes from Jacobian matrix singularity at the voltage collapse point, where the eigenvalues of the reduced Jacobian matrix give an idea of the voltage stable state of the system. This method is far from being used for the practical case as it does not depend directly on system parameters such as impedances, voltage magnitudes or angles. Other useful methods were also introduced in the literature, such as neural networks [8-9], the bifurcation theory energy function [10], etc. However, they have certain disadvantages such as sensitivity to any variation in the network and time for analysis. Some indices linked to a bus or a line were also designed and assessed in voltage stability monitoring. V/V0 is a simple index that can be used, where $V$ is the voltage magnitude in the state of power system operation and $\mathrm{V} 0$ is obtained by solving the power flow with no load connected. A disadvantage of this method is that it is unable to predict the voltage stability margin [11].

Therefore, Moghavvemi et al. [12] have proposed an efficient index called Lmn. This index is sensitive to 
reactive power change. However, it remains insensitive to real power variation. The fast voltage stability index (FVSI) developed by Musirin et al. [13] is derived from the Lmn index by neglecting the voltage angle between the sending and the receiving buses. The line stability index (LQP) proposed by Mohamed et al. [14] is used to predict voltage instability, but it does not take into account real losses in the transmission line. This assumption leads to a poor prediction of network instability. The line stability indices NLSI, changed to NLSI2 to avoid confusion, suggested by Yazdanpanah-Goharrizi et al. [15] and VSI proposed by Chattopadhyay et al. [16], are used for power system monitoring. However, by neglecting angle parameters, simplification employed in these papers affects index accuracy. To address this issue, a combination of indices was proposed by Samuel et al. [17] to develop a line voltage stability index (NLSI1), by taking into account the angle difference parameter. However, this index seems to be complicated as it depends on physical parameters of the electric grid. So any integration of new equipment into the network has to be considered again in the computation such as the installation of the flexible alternating current transmission system (FACTS). For this index, the effect of real power is not considered, which is far from real operating conditions.

All assumptions employed for developing voltage stability indices were used to simplify the computation process and the implementation in the real power system control. Nevertheless, the accuracy of indices was affected and consequently, monitoring of the electric power system has become less effective. Indeed, the power grid can reach its instability zone before the index is in its critical value. Therefore, designing an effective index remains a challenge.

This paper proposes a novel voltage stability index (NVSI) by combining two existing voltage stability indices, i.e., the $L$ index proposed by Rahman et al. [18] and the Lp index introduced by Sahari et al. [19]. The novel index is not only more accurate, but also easily calculated from the results of the load flow program or practically from phasor measurement units (PMU) measurements in real time [20-22]. Its integration into the energy management system (EMS) will be very useful and make it possible to better predict critical situations and the stability margin in the power system. To show the effectiveness of the proposed index, an assessment and discussions will be done using PSAT software which is a MATLAB toolbox for electric power system analysis [23].

\section{THEORETICAL BACKGROUND}

\subsection{DEVELOPMENT OF A NOVEL VOLTAGE STABILITY INDEX}

In general, the voltage stability index is formulated from the characteristics of the voltage collapse point. A single line diagram of the transmission line is shown in Figure 1.

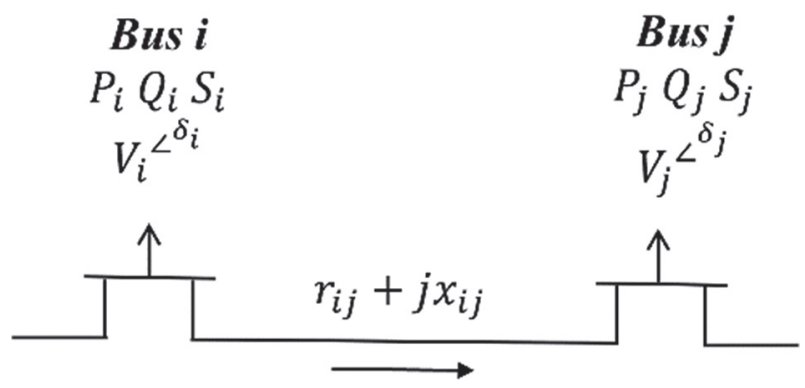

Fig. 1. Two-bus power system model.

The voltage equation is expressed as:

$$
\begin{aligned}
& V_{j}^{4}+V_{j}^{2} \cdot\left[2\left(\mathrm{P}_{j} r_{i j}+Q_{j} x_{i j}\right)-V_{j}^{2}\right]+ \\
& \left(\mathrm{P}_{j}^{2}+Q_{j}^{2}\right)\left(\mathrm{r}_{i j}^{2}+x_{i j}^{2}\right)=0
\end{aligned}
$$

A negative value of the discriminant ensures that the $\mathrm{V}$. expression has no real value, so it must be greater than or equal to zero:

$$
\begin{aligned}
& 8 P_{j} Q_{j} r_{i j} x_{i j}-4 V_{i}^{2}\left(P_{j} r_{i j}+Q_{j} x_{i j}\right)+ \\
& V_{i}^{4}-4\left(P_{j}^{2} x_{i j}^{2}+Q_{j}^{2} r_{i j}^{2}\right) \geq 0
\end{aligned}
$$

Equation (2) is written as:

$$
\frac{4\left[V_{i}^{2}\left(P_{j} r_{i j}+Q_{j} x_{i j}\right)+\left(P_{j} x_{i j}-Q_{j} r_{i j}\right)^{2}\right]}{V_{i}^{4}} \leq 1
$$

hence we have:

$$
P_{j} r_{i j}+Q_{j} x_{i j}=V_{i} V_{j} \cos \left(\delta_{i}-\delta_{j}\right)-V_{j}^{2},
$$

and

$$
\begin{gathered}
P_{j} x_{i j}-Q_{j} r_{i j}=V_{i} V_{j} \sin \left(\delta_{i}-\delta_{j}\right) \\
L=\frac{4\left[V_{i} V_{j} \cos (\delta)-V_{j}^{2} \cos ^{2}(\delta)\right]}{V_{i}^{2}},
\end{gathered}
$$

where $\delta=\delta_{i}-\delta_{j}$. To ensure voltage stability, L must be less than unity.

If we consider that the angle voltage difference is very small $(\cos (\delta)=1)$, then $\mathrm{L}$ can be simplified according to the following expression [19]:

$$
L_{p}=\frac{4\left[V_{i} V_{j}-V_{j}^{2}\right]}{V_{i}^{2}}
$$


This index seems to be more simplified as it depends only on voltage magnitude which can considerably reduce the computation time and the memory allocated for variables or for the computation algorithm. The suitability of this index will also be relevant in dynamic analysis. However, the considered simplification should not be applied under any load condition. The angle difference is one of the parameters that can lead to instability of the power system. It becomes more important when it is near to the stability limit [17]. Moreover, this justifies the use of angle as a voltage stability margin predictor [24].

Shortly, despite the simplicity of the Lp index, it will remain insufficient, especially in large loads. At voltage collapse it must be equal to 1 and any other different value will not qualify this index as a reliable one. For this reason, the novel voltage stability index (NVSI) will be expressed as follows:

$$
\begin{aligned}
& N V S I=\alpha L+(1-\alpha) \mathrm{L}_{p}, \\
& \alpha=\left\{\begin{array}{lc}
0 & \text { if } \quad \delta \leq \delta_{\text {Threshold }} \\
1 & \text { otherwise }
\end{array}\right.
\end{aligned}
$$

since the simplification made to migrate from $L$ to $L p$ is based on the approximation taken on the angle gap. The threshold angle $\delta_{\text {Threshold }}$ will be taken when $\cos (\delta)$ is assumed to be equal to 1 (the case of low loads).

The computation of the NVSI can be calculated by using two steps for each PQ bus, like the L index [18][25], as follows:

Step 1: Load flow solutions are used to determine voltage magnitude $V_{j}$ and angle $\delta_{j}$ of the power system at a given load condition.

Step 2: $V_{i}$ and $\delta_{i}$ are obtained by the load flow of the power system after removing the load at the concerned bus.

\subsection{INDEX PARAMETER DETERMINATION}

\subsubsection{Case study}

A single line diagram of the IEEE 14-bus standard system is shown in Figure 2. It represents a simple approximation of a portion of the American electric power system. Basically, it has 14 buses, 20 interconnected branches, 5 generators, 3 transformers and 9 load bus bars.

\subsubsection{Index parameter}

For each node of the network, the apparent load is increased by an apparent load factor (the power factor is maintained constant). Three $\mathrm{PQ}$ buses were randomly chosen to be assessed, i.e., bus 10, bus 13, and bus 14 . The following graph (Figure 3) shows index evolution for any multiplication of apparent power of the concerned bus by the load factor.

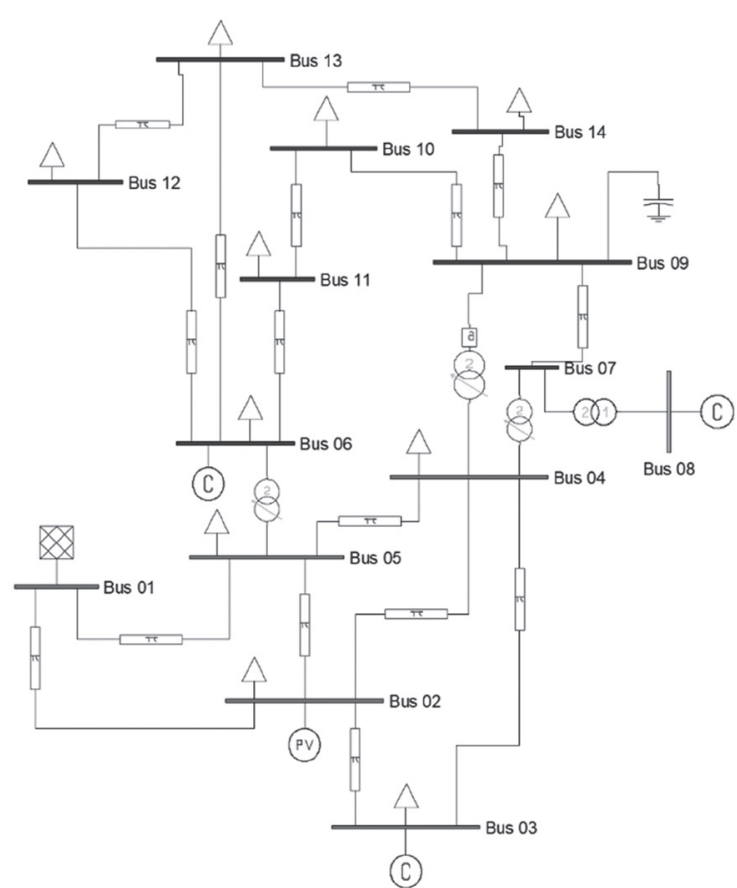

Fig. 2. Single line diagram of the IEEE 14-bus test system (a static case)

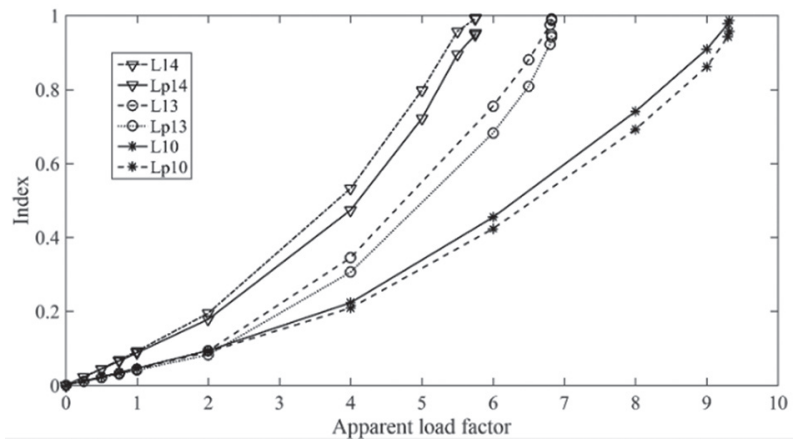

Fig. 3. $L$ and $L p$ index evolution

As shown in Figure 3, all indices vary in the same direction as a function of the apparent load factor. Compared to others, they evolve rapidly in bus 14, which proves the sensitivity of this area and its loadability limits in the power system under study. It can also be noted that as we get closer to the critical point where the indices approach the unity, voltage magnitudes decrease and the angle gap $\delta$ becomes more important. Figures 4 and 5 confirm this observation with respect to the angle. As shown in these figures, the simplification made on the angles will be invalid when a high load is applied and remains valid for low loads.

Based on simulation results (figures 3, 4, and 5), for any low load, the angle gap is very small. Then, the original index (L) can be simplified and replaced by the derived one (Lp), which will simplify the calculation procedure. Indeed, the index will be calculated only from voltage magnitudes.

On the other hand, if the apparent load increases in the concerned bus, an increase in the angle gap between the sending and receiving buses will be 
observed. This is the result of the increase in the real power flowing through the equivalent line. For this scenario, the angle difference becomes more significant. Therefore, it will be included when calculating the index. Otherwise, index accuracy will be affected.

We focus on the critical bus 14 and the base case where the apparent load factor is equal to the unity. The angle gap between the sending and receiving buses is equal to $\delta=2.72 \mathrm{deg}$. It will be considered as the threshold from where $L p$ has to be replaced by L. For this case, L14 and Lp14 are equal to 0.0922 and 0.0879, respectively.

If we consider the latest results, we can use the proposed NVSI index to assess voltage stability at bus 14 . Figure 6 represents a variation of this index according to the variation of the apparent load at same bus. Unti the base case, NVSI is equivalent to Lp, then it takes the values of $\mathrm{L}$.

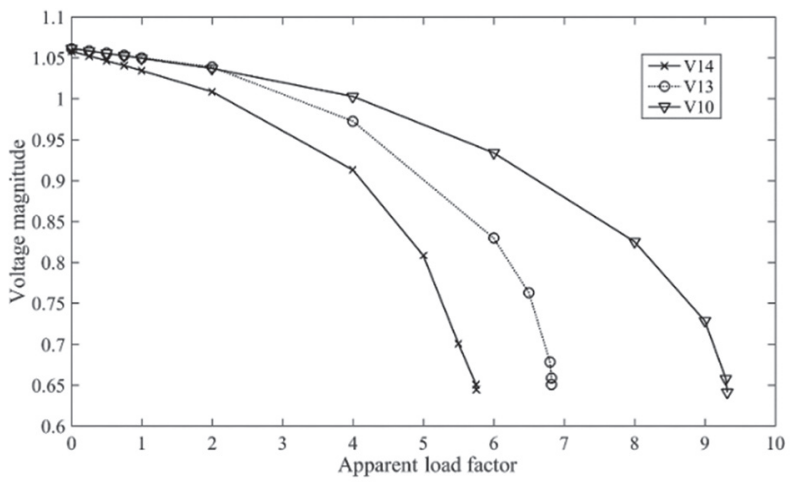

Fig. 4. Voltage magnitude vs apparent load factor

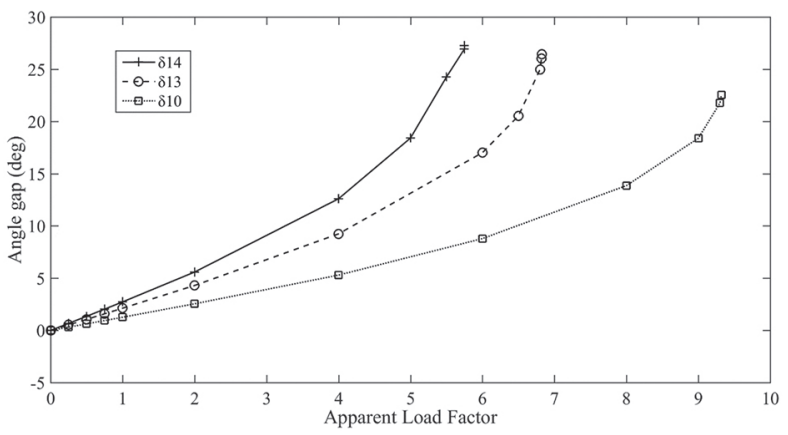

Fig. 5. Angle gap vs apparent load factor

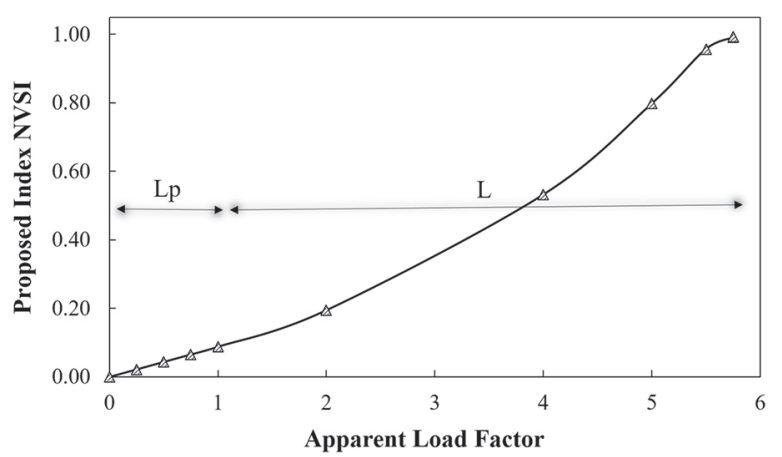

Fig. 6. NVSI evolution at bus 14
The NVSI index can also be plotted against $L$ and $L p$ (Figure 7).

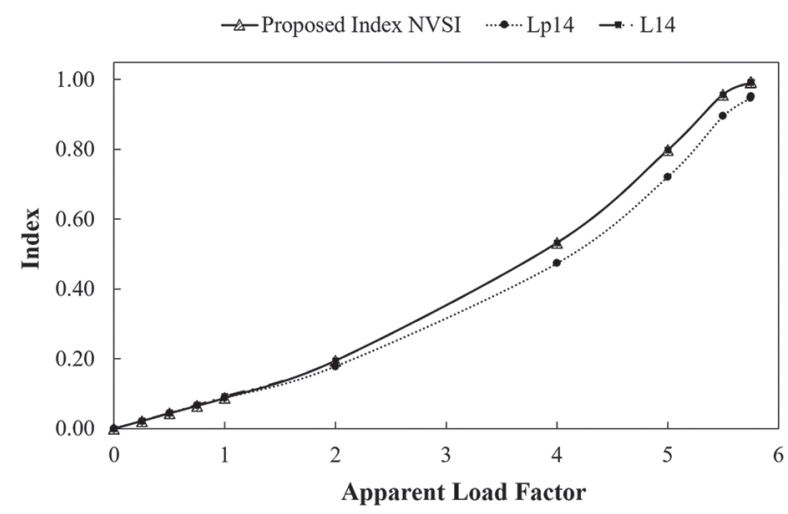

Fig. 7. L, Lp, and NVSI at bus 14 vs apparent load factor

It can be seen from Figure 7 that the indices are almost identical for low loads, while at high load, Lp does not correctly predict a degree of voltage stability. For this case, NVSI is identical to L.

\section{SIMULATION AND RESULTS}

\subsection{INDEX REFORMULATION AND COMPARISON}

In order to make a comparison with some indices already reported in the literature, first we need to reformulate them in order to have the same dimensions. It means that for a line index, it can become a bus index by using the reduced local network as shown in Figure 8 .

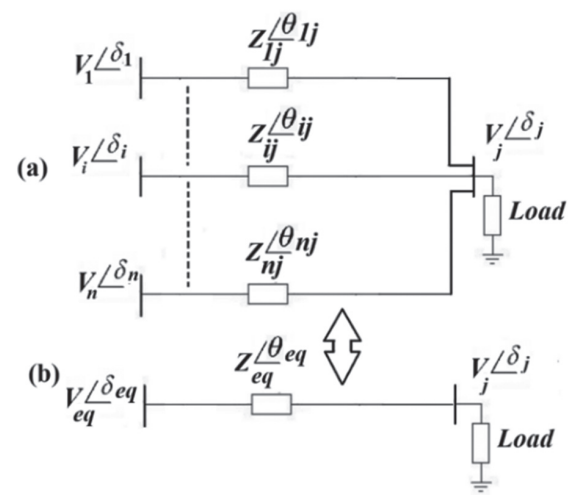

Fig. 8. (a) Power system seen from bus j (b) Reduced equivalent network

In the reduced network, the equivalent voltage as seen by the node can be computed by the following formulas:

$$
\underline{V_{e q}}=\frac{\sum_{i=1}^{n} \frac{V_{i}}{\frac{Z_{i j}}{}}}{\sum_{i=1}^{n} \frac{1}{Z_{i j}}}
$$


The equivalent impedance can be expressed as:

$$
\underline{Z_{e q}}=\frac{1}{\sum_{i=1}^{n} \frac{1}{Z_{i j}}}
$$

To avoid confusion with the original index formula, we added an " $r$ " index following the use of the reduced network.

Table 1 summarizes 6 index formulas and their critical values for the reduced network. For the NLSI1 index, the value of the switching angle considered by Samuel et al. [17] is equal to 1.422 deg. In this paper, using a comparative approach, the value that can be taken is similar to the one used for the proposed index $\left(\delta_{\text {Threshold }}=2.72 \mathrm{deg}\right)$.

Table 1. Index reformulation

\begin{tabular}{|c|c|c|c|c|}
\hline Index & $\begin{array}{l}\text { Original } \\
\text { name }\end{array}$ & $\begin{array}{l}\text { Formula (applied to } \\
\text { reduced network) }\end{array}$ & $\begin{array}{l}\text { Critical } \\
\text { value }\end{array}$ & Ref. \\
\hline FVSIr & FVSI & $\frac{4 Q_{j}\left|Z_{e q}\right|^{2}}{\left|\underline{V_{e q}}\right|^{2} \operatorname{imag}\left(\underline{Z_{e q}}\right)}$ & 1 & [13] \\
\hline Lmnr & Lmnr & $\frac{4 Q_{j} X_{e q}}{\left|\underline{V_{e q}}\right|^{2} \sin ^{2}\left(\theta_{e q}-\delta\right)}$ & 1 & [12] \\
\hline NLSI1r & NLSI1 & $\frac{4 Q_{j}}{\left|\underline{V_{e q}}\right|^{2}}\left(\frac{\left|Z_{e q}\right|^{2}}{\operatorname{imag}\left(\underline{\left.Z_{e q}\right)}\right.} \sigma-\frac{\operatorname{imag}\left(\underline{Z_{e q}}\right)}{\sin ^{2}\left(\theta_{e q}-\delta\right)}(\sigma-1)\right)$ & 1 & [17] \\
\hline $\mathrm{NLSI} 2 \mathrm{r}$ & NLSI & $\frac{P_{j} \cdot \operatorname{real}\left(\underline{\left.Z_{e q}\right)}+Q_{j} \cdot \operatorname{imag}\left(\mathrm{Z}_{e q}\right)\right.}{0.25\left|V_{e q}\right|^{2}}$ & 1 & [15] \\
\hline LQPr & LQP & $4\left(\frac{\operatorname{imag}\left(Z_{e q}\right)}{\left|V_{e q}\right|^{2}}\right)\left(Q_{j}+\frac{P_{e q}^{2} \cdot \operatorname{imag}\left(Z_{e q}\right)}{\left|V_{e q}\right|^{2}}\right)$ & 1 & [14] \\
\hline VSIr & VSI & $\frac{4 Q_{j}\left(\operatorname{real}\left(Z_{e q}\right)+\operatorname{imag}\left(\underline{Z_{e q}}\right)\right)^{2}}{\operatorname{imag}\left(\underline{Z_{e q}}\right)\left(\left|V_{e q}\right|^{2}+8 \operatorname{real}\left(\underline{Z_{e q}}\right) \cdot Q_{j}\right)}$ & 1 & [16] \\
\hline
\end{tabular}

Based on index reformulation given in Table 1, the first comparison can be performed using the number of inputs of each index, as summarized in Table 2.

Table 2. Details of each voltage stability index inputs

\begin{tabular}{ccc|}
\hline Index & Type of inputs & Number of input types \\
\hline FVSIr & $\mathrm{X}, \mathrm{Z}, \mathrm{V}, \mathrm{Q}$ & 4 \\
\hline Lmnr & $\mathrm{X}, \theta, \mathrm{V}, \mathrm{Q}, \mathrm{\delta}$ & 5 \\
\hline NLSI1r & $\mathrm{X}, \theta, \mathrm{V}, \mathrm{Q}, \mathrm{\delta}, \mathrm{\sigma}$ & 6 \\
\hline NLSI2r & $\mathrm{R}, \mathrm{Z}, \mathrm{V}, \mathrm{P}, \mathrm{Q}$ & 5 \\
\hline LQPr & $\mathrm{Z}, \mathrm{V}, \mathrm{P}, \mathrm{Q}$ & 4 \\
\hline VSIr & $\mathrm{R}, \mathrm{X}, \mathrm{V}, \mathrm{Q}$ & 4 \\
\hline $\mathrm{L}$ & $\mathrm{V}, \delta$ & 2 \\
\hline Lp & $\mathrm{V}$ & 1 \\
\hline NVSI & $\mathrm{V}, \delta, a$ & 3 \\
\hline
\end{tabular}

It appears from Table 2 that the voltage stability index developed in this paper has 3 types of inputs. However, it should be noted that depending on the value of " $a$ ", NVSI becomes $L$ with two inputs or Lp with one kind of inputs (voltage magnitude).

\subsection{REAL LOAD INCREASE}

One of the current problems is to succeed in predicting voltage instability following an increase in real load in the power system.

In order to assess the performance of the proposed index for an increase in real power with respect to others, real power is changed in bus 14 . It is increased by the real load factor until load flow does not converge (equation 12).

$$
P_{l}=\lambda_{a} \cdot P_{0}
$$

where P0 is real load power at bus 14 in the base case.

As shown in Figure 9, when real power increases in bus 14 , the voltage of the concerned bus decreases and the power system is running to a state of voltage instability which causes voltage collapse. On the other hand, NVSI shows more sensitivity when compared to real load variation.

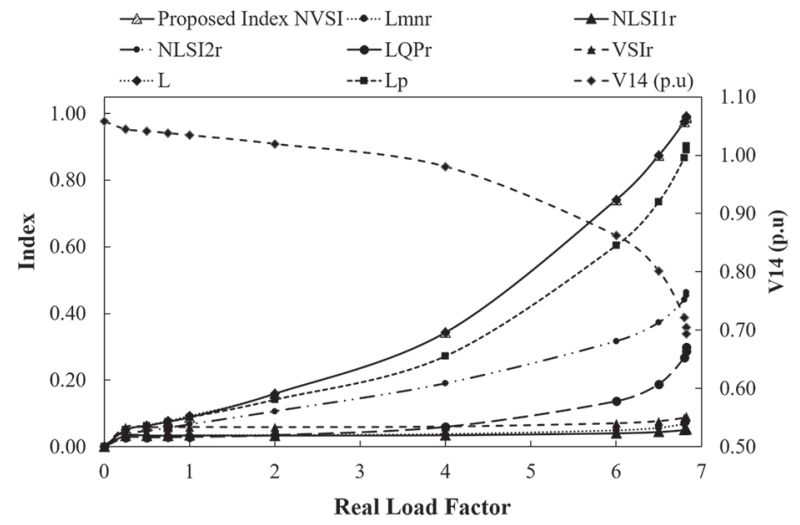

Fig. 9. Indices at bus 14 vs real power variation

Figure 9 confirms that the indices do not have the same rate of change. To further clarify these points, analysis of the stability margin is discussed below.

\subsection{SPECIFIC LOAD AND VOLTAGE STABILITY MARGIN PREDICTION}

Based on the results presented in Figure 9, the values of each index and the stability margin for three cases depending on the load value at node 14 are given in Table 3.

The stability margin is obtained when the load flow does not converge. This method is considered as one of the most accurate ones for a voltage stability margin assessment. 
Table 3. Indices values and stability margin

\begin{tabular}{cccccccc} 
& \multicolumn{2}{c}{ Case 1 : } & \multicolumn{2}{c}{ Case 2: } & \multicolumn{2}{c}{ Case 3: } \\
Index & 0.5*Base Case & \multicolumn{2}{c}{$\begin{array}{c}\text { Base Case } \\
\text { Critical Case }\end{array}$} \\
& $\begin{array}{c}\text { Index } \\
\text { Value }\end{array}$ & $\begin{array}{c}\text { Rower } \\
\text { Pargin } \\
\text { (p.u) }\end{array}$ & $\begin{array}{c}\text { Index } \\
\text { Value }\end{array}$ & $\begin{array}{c}\text { Real } \\
\text { Power } \\
\text { Margin } \\
\text { (p.u) }\end{array}$ & $\begin{array}{c}\text { Index } \\
\text { Value }\end{array}$ & $\begin{array}{c}\text { Real } \\
\text { Power } \\
\text { Margin } \\
\text { (p.u) }\end{array}$ \\
\hline FVSIr & 0.0337 & 0.94 & 0.0340 & 0.87 & 0.0530 & 0 \\
\hline Lmnr & 0.0339 & 0.94 & 0.0346 & 0.87 & 0.0749 & 0 \\
\hline NLSI1r & 0.0337 & 0.94 & 0.0346 & 0.87 & 0.0749 & 0 \\
\hline NLSI2r & 0.0469 & 0.94 & 0.0670 & 0.87 & 0.4634 & 0 \\
\hline LQPr & 0.0278 & 0.94 & 0.0294 & 0.87 & 0.2995 & 0 \\
\hline VSIr & 0.0588 & 0.94 & 0.0590 & 0.87 & 0.0906 & 0 \\
\hline L & 0.0634 & 0.94 & 0.0922 & 0.87 & 0.9922 & 0 \\
\hline LP & 0.0625 & 0.94 & 0.0879 & 0.87 & 0.9034 & 0 \\
\hline NVSI & 0.0625 & 0.94 & 0.0879 & 0.87 & 0.9922 & 0 \\
\hline
\end{tabular}

Table 3 shows that all indices take a very stable values in case 1 and case 2 (base case). However, FVSIr, Lmnr, NLSI1r, VSIr are less sensitive when moving from case 1 to case 2 , even if the stability margin is reduced from $0.94 \mathrm{pu}$ to $0.87 \mathrm{pu}$. The worst is observed when the stability limit is reached (case 3 ). In this case, it can be noticed that the same indices (FVSIr, Lmnr, NLSI1r, VSIr) remain practically unchanged, which is also shown in Figure 9. It can also be observed that some indices are still far from 1, which normally corresponds to the stability limit already presented in Table 1.

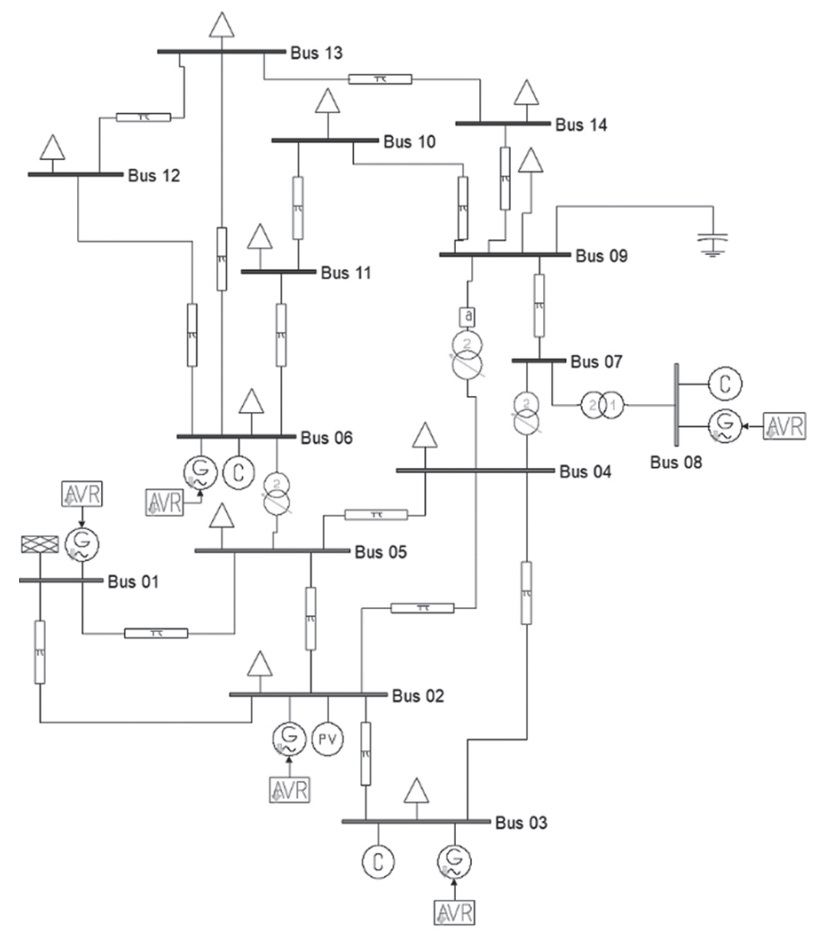

Fig. 10. Single line diagram of the IEEE 14-bus test system (a dynamic case
This is unacceptable because it indicates that the instability zone is still far away, which is not true. The same remark is made on the Lp index at the stability limit. On the other hand, NVSI allows better monitoring of all these load variations and it can even be remarked that NVSI as well as L in large loads allow to predict the stability limit correctly.

\subsection{DYNAMIC ANALYSIS (LOAD VARIATION)}

It takes a long time to complete and perform dynamic analysis. For this reason, the proposed index can be very useful as a powerful and economical tool for monitoring the power system. However, it must be evaluated and compared to other indices. To do this, we used temporal analysis involving dynamic components of the IEEE 14-bus network, as shown in Fig. 10.

Load variation is considered as a disturbance and it is applied after each stabilization of the voltage in bus 14 . The load is changed after each time interval, as shown in Figure 11. As a reference, real and reactive loads at bus 14 are set to 0.149 pu and 0.05 pu, respectively. Figure 12 illustrates a dynamic variation of voltage magnitude and the angle gap at bus 14 .

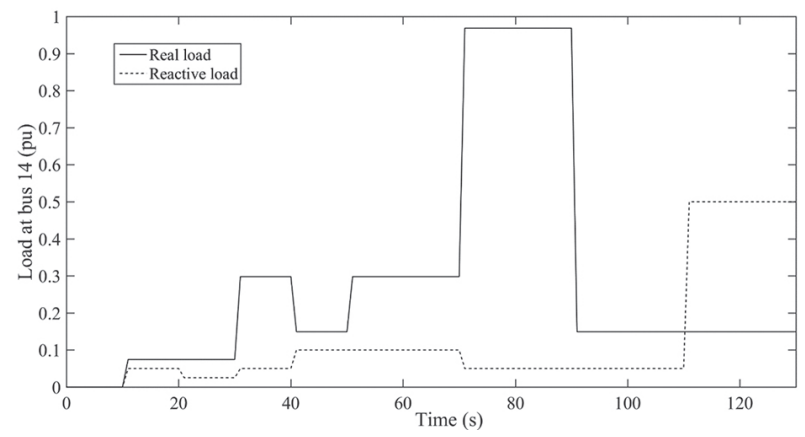

Fig. 11. Load profile at bus 14

The graph shown in Figure 12 depicts a change in bus 14 voltage due to a change in active and reactive loads. Oscillations and damping observed in some intervals are mainly caused by the operating point change caused by new loads.

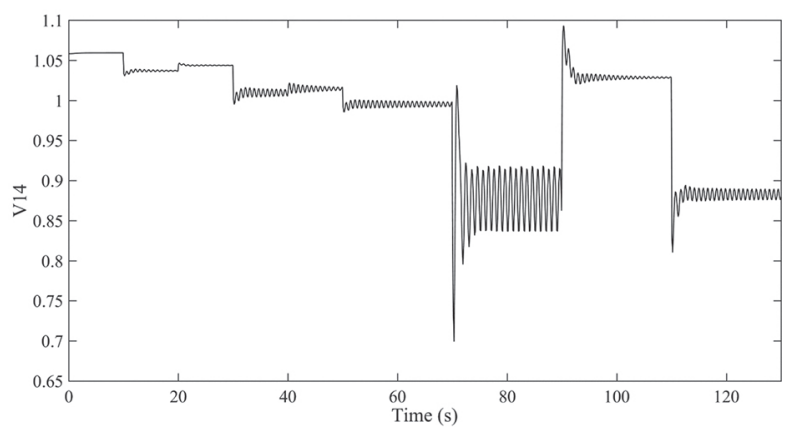

Fig. 12. Voltage magnitude at bus 14

For the proposed index in this contribution, we plot the angle gap variation in Figure 13. This will allow us to view the switching angle fixed in our case to $2.72 \mathrm{deg}$. 
The NVSI index will be replaced by the Lp index when the angle is less than the critical value, whereas in the opposite case, the NVSI index will be replaced by the $\mathrm{L}$ index.

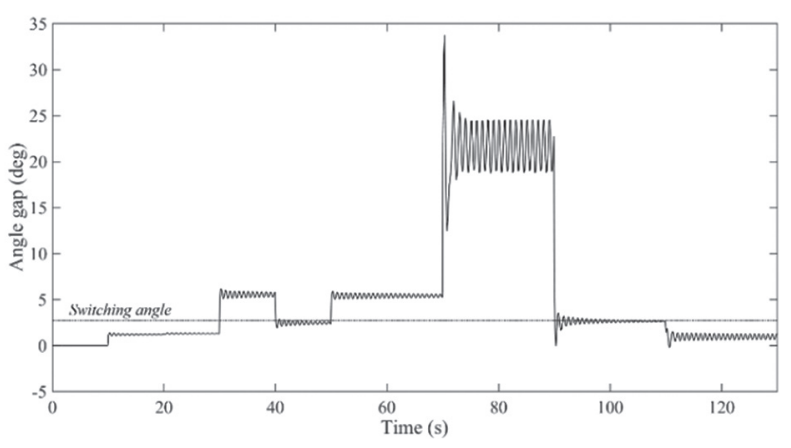

Fig. 13. Angle gap

Figure 14 presents the profile of voltage stability indices examined in this paper. Index performance is analyzed by the results illustrated in figures 12,13 and 14 .

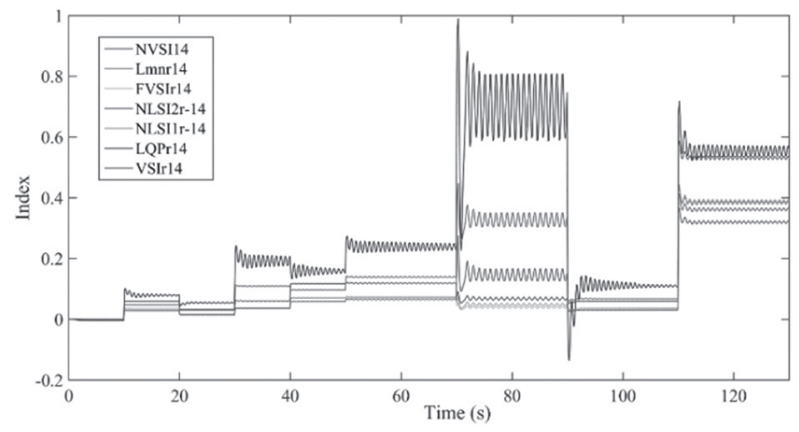

Fig. 14. Index at bus 14

At time $0 \mathrm{~s}$, no load is connected to bus 14 and all indices remain at zero level. At $t=10 \mathrm{~s}$, to bus 14 we applied the reference value of reactive power and half of the reference value of active power. We observe that the magnitude voltage decreases and all indices increase and seem sensitive to this disturbance. At $t=20 \mathrm{~s}$, when we used half of the reference values of reactive and active powers as load, all indices decrease and the voltage amplitude increases. For the time interval between 30 and $40 \mathrm{~s}$, an increase in active power on bus 14 by $200 \%$ leads to voltage drop across the power system.

Compared to other indices examined in this paper, NVSI and NLSI2r indices seem to be more sensitive to the applied disturbances. At $t=40 \mathrm{~s}$, the reactive load was increased by $200 \%$, while keeping the value of active power at its reference value. NVSI is equivalent to the voltage stability index Lp and has high sensitivity to the variation of the load and voltage magnitude. At the time of $50 \mathrm{~s}$, the values of active and reactive powers were increased by $200 \%$ on bus 14 .

This disturbance leads to a decrease in the voltage amplitude and to an increase in the NVSI index which is equivalent to the $L$ index since the angle difference is large, as shown in Figure 13. Similarly, the NLSI2r index has a sensitivity level that is acceptable but less than the sensitivity level of the new NVSI developed in this paper. The application at $70 \mathrm{~s}$ of a heavy real load fixed at $0.96 \mathrm{pu}$ in bus node 14 leads to a sharp drop in voltage and a sharp increase in the new NVSI index compared to other indices showing a small or negligible variation with respect to the perturbation applied. At $90 \mathrm{~s}$, the values of active and reactive powers were fixed $0.149 \mathrm{pu}$ and at $0.5 \mathrm{pu}$, respectively. This disturbance leads to the voltage drop at node 14 and to an increase in the value of all indices tested in this paper. From this analysis, we conclude that the new index developed is very sensitive to different loads applied to bus node 14 and remains to be the best one compared to indices examined.

\section{CONCLUSION}

In this paper, we have proposed a novel index (NVSI) for analyzing voltage stability in a power system. It is derived from a combination of two indices defined in the literature and offers various advantages such as simplicity, accuracy and sensitivity.

Static and dynamic analyses have been conducted on the IEEE 14-bus test system and the switching angle has been specified to change the proposed index from one value to another. The new index has also proved more sensitivity to a disturbance for any kind of change in active and reactive loads. It could be then considered as an alternative to monitoring and predicting voltage collapse proximity.

The proposed index can be easily incorporated as an advanced function with the energy management system (EMS) and used with load shedding schemes. However, future studies should take into account the size of a power system.

\section{REFERENCES:}

[1] T. Huang, S. L. Voronca, A. A. Purcarea, A. Estebsari, E. Bompard, "Analysis of chain of events in major historic power outages", Advances in Electrical and Computer Engineering, Vol. 14, No. 3, 2014, pp. 63-70.

[2] Y. K. Wu, S. M. Chang, Y. L. Hu, "Literature Review of Power System Blackouts", Energy Procedia, Vol. 141, 2017, pp. 428-431.

[3] R. Chen, X. Sun, G. Liu, “Fault Localization for Synchrophasor Data using Kernel Principal Component Analysis", Advances in Electrical and Computer Engineering, Vol. 17, No. 4, 2017, pp. 37-42.

[4] J. G. Calderón-Guizar, E. A. Tovar-González, "Impact on generator reactive power limits on a static volt- 
age stability", Advances in Electrical and Computer Engineering, Vol. 11, No. 4, 2011, pp. 105-110.

[5] J. Hossain, H. R. Pota, "Power system voltage stability and models of devices", Robust control for grid voltage stability: high penetration of renewable energy, pp. 19-59, Springer, Singapore, 2014.

[6] A. Z. De Souza, F. W. Mohn, I. F. Borges, T. R. Ocariz, "Using PV and QV curves with the meaning of static contingency screening and planning", Electric Power Systems Research, Vol. 81, No. 7, 2011, pp. 1491-1498.

[7] B. Gao, G. K. Morison, P. Kundur, "Voltage stability evaluation using modal analysis", IEEE Transactions on Power Systems, Vol. 7, No. 4, 1992, pp. 1529-1542.

[8] W. Nakawiro, I. Erlich, "Online voltage stability monitoring using artificial neural network", Proceedings of the 3rd International Conference on Electric Utility Deregulation and Restructuring and Power Technologies, Nanjing, China, 6-9 April 2008, pp. 941-947.

[9] S. Chakrabarti, B. Jeyasurya, "On-line voltage stability monitoring using artificial neural network", Proceedings of the 2004 Large Engineering Systems Conference on Power Engineering, Halifax, NS, Canada, 28-30 July 2004, pp. 71-75.

[10] T. J. Overbye, C. L. DeMarco, "Improved techniques for power system voltage stability assessment using energy methods", IEEE Transactions on Power Systems, Vol. 6, No. 4, 1991, pp. 1446-1452.

[11] S. Sen, S. Sengupta, A. Chakrabarti, "Analysis of Voltage Stability of Longitudinal Power Supply System Using an Artificial Neural Network", Electricity Pricing, Regulated, Deregulated and Smart Grid Systems, pp. 29-64, CRC Press, 2015.

[12] M. Moghavvemi, F. M. Omar, "Technique for contingency monitoring and voltage collapse prediction", IEE Proceedings-Generation, Transmission and Distribution, Vol. 145, No. 6, 1998, pp. 634-640.

[13] I. Musirin, T. A. Rahman, "Novel fast voltage stability index (FVSI) for voltage stability analysis in power transmission system", Proceedings of the 2002 Student Conference on Research and Development, Shah Alam, Malaysia, 17 July 2002, pp. 265-268.

[14] A. Mohamed, G. B. Jasmon, S. Yusoff, "A static volt- age collapse indicator using line stability factors", Journal of Industrial Technology, Vol. 7, No. 1, 1989, pp. 73-85.

[15] A. Yazdanpanah-Goharrizi, R. Asghari, "A novel line stability index (NLSI) for voltage stability assessment of power systems", Proceedings of the 7th WSEAS International Conference on Power Systems, Beijing, China, 15-17 September 2007, pp. 164-167.

[16] T. K. Chattopadhyay, S. Banerjee, C. K. Chanda, "Impact of distributed generator on voltage stability analysis of distribution networks under critical loading conditions", Proceedings of the 1st International Conference on Non Conventional Energy, Kolkata, India, 16-17 January 2014, pp. 288-291.

[17] I. A. Samuel, J. Katende, C. O. Awosope, A. A. Awelewa, "Prediction of Voltage Collapse in Electrical Power System Networks Using a New Voltage Stability Index", International Journal of Applied Engineering Research, Vol. 12, No. 2, 2017, pp. 190-199.

[18] T. A. Rahman, G. B. Jasmon, "A new technique for voltage stability analysis in a power system and improved loadflow algorithm for distribution network", Proceedings of the 1995 International Conference on Energy Management and Power Delivery, Singapore, 21-23 November 1995, pp. 714-719.

[19] S. Sahari, A. F. Abidin, T. A. Rahman, “Development of artificial neural network for voltage stability monitoring", Proceeding the 2003 National Power Engineering Conference, Bangi, Malaysia, 15-16 December 2003, pp. 37-42.

[20] D. T. Duong, K. Uhlen, "Online voltage stability monitoring based on PMU measurements and system topology", Proceedings of the 3rd International Conference on Electric Power and Energy Conversion Systems, Istanbul, Turkey, 2-4 October 2013, pp. 1-6.

[21] M. K. H. Pulok, M. O. Faruque, "Utilization of PMU data to evaluate the effectiveness of voltage stability boundary and indices", Proceedings of the 2015 North American Power Symposium, Charlotte, NC, USA, 4-6 October 2015, pp. 1-6.

[22] A. Kulanthaisamy, R. Vairamani, N. K. Karunamurthi, C. Koodalsamy, "A multi-objective PMU placement method considering observability and measurement redundancy using $A B C$ 
algorithm", Advances in Electrical and Computer Engineering, Vol. 14, No. 2, 2014, pp. 117-128.

[23] L. Vanfretti, F. Milano, "Application of the PSAT, an open source software, for educational and research purposes", Proceedings of the 2007 IEEE Power Engineering Society General Meeting, Tampa, FL, USA, 24-28 June 2007, pp. 1-7.

[24] T. He, S. Kolluri, S. Mandal, F. Galvan, P. Rasigoufard, "Identification of weak locations in bulk transmis- sion systems using voltage stability margin index", Proceedings of the 2004 IEEE Power Engineering Society General Meeting, Denver, CO, USA, 6-10 June 2004, pp. 1814-1819.

[25] H. H. Goh, Q. S. Chua, S. W. Lee, B. C. Kok, K. C. Goh, K. T. K. Teo, "Evaluation for voltage stability indices in power system using artificial neural network", Procedia Engineering, Vol. 118, 2015, pp. 11271136. 